\section{Effects of \\ intravitreal gas with \\ or without tissue \\ plasminogen \\ activator on \\ submacular \\ haemorrhage in \\ age-related macular degeneration}

I-M Fang ${ }^{1,2}$, Y-C Lin'1 , C-H Yang ${ }^{1}$, C-M Yang ${ }^{1}$ and M-S Chen ${ }^{1}$

\begin{abstract}
Purpose To compare the anatomic and functional outcomes of treating thick submacular haemorrhage with intravitreal gas injection with and without tissue plasminogen activator (t-PA) in patients with age-related macular degeneration.

Methods A review of age-related macular degeneration patients with submacular haemorrhage who underwent intravitreal gas injection with and without t-PA at a tertiary referral centre was conducted. Main outcome measures were best and final postoperative visual acuity.

Results A total of 53 eyes of 53 patients were included, 28 eyes received intravitreal $t-P A$ and gas injection (t-PA and gas group) and 25 eyes received intravitreal gas injection alone (gas-alone group). Incidence of best visual acuity improvement was significantly higher in the t-PA and gas group than in the gas-alone group (60.7 vs $32.0 \% ; P=0.037$ ). However, subgroup analysis demonstrated that the difference was significant only in eyes with haemorrhage duration of more than 14 days (46.2 vs $8.3 \% ; P=0.035$ ). Incidence of final visual acuity improvement was not significantly different between the two groups (42.9 vs $28.0 \% ; P=0.39$ ). The complications of vitreous haemorrhage and endophthalmitis were similar between the two groups. Multiple logistic regression analysis demonstrated that shorter haemorrhage duration ( $<\mathbf{1 4}$ days) was the main factor predictive of best visual acuity improvement
\end{abstract}

$(\mathrm{OR}=9.02, P=0.015)$. Whether $\mathrm{t}-\mathrm{PA}$ was used was of borderline significance $(O R=4.96$, $P=$ 0.046).

\section{Abstract \\ Conclusions Intravitreal t-PA was valuable for submacular haemorrhage only in eyes with relatively old haemorrhage. For eyes with recent onset of haemorrhage, t-PA is suggested only if initial gas injection failed to displace} submacular haemorrhage.

Eye (2009) 23, 397-406; doi:10.1038/sj.eye.6703017; published online 2 November 2007

Keywords: age-related macular degeneration; tissue plasminogen activator; submacular haemorrhage; pneumatic displacement

\section{Introduction}

Submacular haemorrhage is a significant cause of visual loss in patients with age-related macular degeneration (AMD). ${ }^{1-4}$ Shearing of photoreceptors by a fibrin clot, physical separation of photoreceptors from the retinal pigment epithelium, iron toxicity, and blockage of nutrient diffusion have been proposed as explanations for the retinal damage caused by thick subretinal blood. 5,6 The potential for vision loss has prompted investigation of safe and effective methods for removing thick blood beneath the macula, to speed visual recovery, and prevent irreversible blood-induced damage to the retina.
${ }^{1}$ Department of Ophthalmology, National Taiwan University Hospital, Taipei, Taiwan

\section{${ }^{2}$ Department of} Ophthalmology, Taipei City Hospital, Zhongxiao Branch, Taipei, Taiwan

Correspondence: C-H Yang, Department of

Ophthalmology,

National Taiwan University Hospital,

no 7, Chung-Shan South Road,

Taipei, Taiwan.

Tel: + 886223123456 ext 3193;

Fax: + 886223412875 .

E-mail: chyangoph@

ntu.edu.tw

Received: 22 April 2007

Accepted in revised form: 28 September 2007

Published online:

2 November 2007

The authors have no proprietary interest in any aspect of this study. 
Tissue plasminogen activator (t-PA) is an efficient fibrinolytic agent that has proved successful, when administrated subretinally, in the lysis of submacular haemorrhage blood clots for surgical drainage. ${ }^{7-11}$ Intravitreal injection of t-PA and expansible gas was proposed in 1996 as a less invasive alternative to the surgical removal of submacular haemorrhage. ${ }^{12}$ The technique has since been evaluated, and favourable results have been reported in several published series. ${ }^{13-15}$ However, most of these studies were observational, with no control group to compare the anatomic and visual outcomes of AMD patients treated by gas displacement with and without $t$-PA.

Intravitreal t-PA injection is not free of untoward effects. In both animal models and humans, it has been demonstrated to cause retinal toxicity, including bullous retinal detachment, attenuation of retinal vessels, and marked reduction in electroretinogram. ${ }^{16-19}$ Additionally, experimental studies have shown conflicting results as to whether t-PA injected intravitreally can access the subretinal space in sufficient quantities to liquefy submacular blood clots. ${ }^{20-22}$ Furthermore, Ohji et al ${ }^{23}$ have reported success in pneumatic displacement of subretinal haemorrhage with intravitreal injection of gas alone, without t-PA. The conflicting results and potential toxicity of the technique have raised the question of whether adjunctive intravitreal injection of t-PA is in fact safe and superior to gas alone in the management of submacular haemorrhage.

In the current study, we compared the visual and anatomic outcomes as well as the complications of intravitreal gas injection with and without t-PA. We also established a logistic regression model to investigate the possible factors predictive of best postoperative vision improved by two or more Snellen lines in AMD patients with thick submacular haemorrhage treated by gas displacement.

\section{Materials and methods}

The medical records of consecutive AMD patients with thick submacular haemorrhage who had undergone gas displacement with or without intravitreal t-PA injection at the National Taiwan University Hospital by two surgeons (CHY and CMY) between January 1998 and October 2003 were reviewed retrospectively. To be classified as 'thick', the blood under the fovea needed to have caused an obvious elevation of the retina from the retinal pigment epithelium on biomicroscopic examination. All patients were followed postoperatively for at least 6 months.

Each patient underwent complete ophthalmologic examination. Visual acuity was obtained using Snellen charts with manifest refraction or the patient's spectacle correction. Stereoscopic colour fundus photographs of all patients were acquired at initial presentation and each time of the follow-up. Each patient signed a written informed consent as a part of institutional review boardapproved study.

The procedure was performed under topical anaesthesia. The recombinant t-PA solution was prepared by adding $50 \mathrm{ml}$ of a sterile balanced salt solution (Alcon Laboratories, Fort Worth, TX, USA) to a vial containing $50 \mathrm{mg}$ of commercially available t-PA (Actilyse; Boehringer Ingelheim, Ingelheim/Rhein, Germany) and additional dilution was performed to achieve desired doses, using an aseptic technique in a laminar-airflow hood. Following preparation of the bulbar conjunctiva with $5 \%$ betadine solution, $25-50 \mu \mathrm{g}$ of commercial t-PA solution in a volume of $0.1 \mathrm{ml}$ was injected into the midvitreous cavity, through a 30-G needle introduced 3-4 $\mathrm{mm}$ posterior to the limbus superotemporally. The patients were instructed to remain in a supine position for $45 \mathrm{~min}$ before gas injection. Following an aqueous tap to reduce intraocular pressure, $0.3-0.4 \mathrm{ml}$ of perfluoropropane or sulphur hexafluoride gas was injected into the vitreous cavity in a similar fashion. After the procedure, we advised the patients to keep in a prone position as much as possible in the subsequent $72 \mathrm{~h}$ to allow the intraocular gas to displace the blood from the centre of the macula.

Typically, patients were examined 1, 2 weeks, and 1 month after discharge. Thereafter, follow-up was determined by the treating physicians according to the clinical judgment.

Primary outcome measures were (1) degree of blood displacement from under the fovea, (2) best postoperative visual acuity, and (3) final (>6 months) visual acuity. The treating physician measured the degree of blood displacement with an ophthalmoscope and graded it as 'complete', 'partial', or 'no displacement'. Complete displacement was defined as blood clearance of more than $90 \%$ from the subfoveal space, partial displacement as 20-90\% clearance, and no displacement as clearance of less than $20 \%$. Changes in visual acuity were classified as 'improvement' (increase of two or more Snellen visual acuity lines), 'stable' (within two lines from baseline visual acuity), and 'worse' (loss of two or more Snellen visual acuity lines).

Secondary outcome measures included operative complications and t-PA-induced retinal toxicity.

\section{Statistical analysis}

Statistical analysis was performed using SPSS for Windows (Release 10, SPSS Inc., Chicago, IL, USA). Continuous variables were compared across groups using the Student's $t$-test. Discrete variables were 
Table 1 Clinical profile of 53 consecutive patients (53 eyes) with submacular haemorrhage secondary to age-related macular degeneration

\begin{tabular}{|c|c|c|c|c|c|c|c|c|c|c|}
\hline \multirow{2}{*}{$\begin{array}{l}\text { Patient no./sex/ } \\
\text { age(years)/eye }\end{array}$} & \multicolumn{2}{|c|}{ Haemorrhage } & \multirow{2}{*}{$\begin{array}{c}\text { Dose } t-P A \\
\mu g / m l\end{array}$} & \multirow[t]{2}{*}{ Gas } & \multicolumn{3}{|c|}{ Visual acuity } & \multirow[t]{2}{*}{ Displace } & \multirow[t]{2}{*}{ Complication } & \multirow{2}{*}{$\begin{array}{c}\text { Follow-up } \\
\text { (months) }\end{array}$} \\
\hline & $\begin{array}{c}\text { Duration } \\
\text { (days) }\end{array}$ & $\begin{array}{l}\text { Area } \\
\text { (DD) }\end{array}$ & & & Initial & Best & Final & & & \\
\hline $1 / \mathrm{M} / 57 / \mathrm{OS}$ & 12 & 8 & $25 / 0.05$ & SF6 & $\mathrm{HM}$ & HM & HM & C & & 10 \\
\hline 2/F/74/OS & 90 & 4 & $25 / 0.05$ & $\mathrm{C} 3 \mathrm{~F} 8$ & $20 / 400$ & $20 / 100$ & $20 / 200$ & $\mathrm{P}$ & & 16 \\
\hline $3 / \mathrm{M} / 50 / \mathrm{OD}$ & 11 & 6 & $50 / 0.05$ & SF6 & CF & $20 / 100$ & $20 / 100$ & $\mathrm{C}$ & & 9 \\
\hline 4/F/61/OS & 10 & 8 & $50 / 0.05$ & SF6 & $\mathrm{CF}$ & CF & $\mathrm{CF}$ & $\mathrm{N}$ & & 10 \\
\hline 5/F/62/OD & 7 & 5 & $50 / 0.05$ & SF6 & $\mathrm{HM}$ & $20 / 70$ & $20 / 100$ & C & & 16 \\
\hline 6/M/78/OD & 30 & 4 & $50 / 0.05$ & SF6 & HM & $20 / 40$ & $20 / 100$ & C & & 13 \\
\hline 7/F/56/OD & 7 & 7.5 & $50 / 0.05$ & SF6 & $20 / 100$ & $20 / 50$ & $20 / 60$ & $\mathrm{P}$ & & 12 \\
\hline $8 / \mathrm{F} / 50 / \mathrm{OD}$ & 5 & 7 & $50 / 0.1$ & SF6 & HM & $20 / 40$ & $20 / 80$ & $\mathrm{C}$ & $\mathrm{VH}$ & 20 \\
\hline $9 / \mathrm{M} / 62 / \mathrm{OD}$ & 3 & 3 & $25 / 0.1$ & SF6 & $20 / 200$ & $20 / 70$ & $20 / 100$ & $\mathrm{C}$ & & 24 \\
\hline $10 / \mathrm{M} / 62 / \mathrm{OS}$ & 21 & 6 & & SF6 & $20 / 400$ & $20 / 200$ & $20 / 400$ & $\mathrm{P}$ & & 12 \\
\hline $11 / \mathrm{M} / 75 / \mathrm{OD}$ & 9 & 4 & & SF6 & HM & $20 / 100$ & $20 / 200$ & $\mathrm{C}$ & & 16 \\
\hline 12/F/58/OD & 30 & 4 & $50 / 0.05$ & SF6 & $20 / 400$ & $20 / 100$ & $20 / 200$ & $\mathrm{C}$ & & 23 \\
\hline $13 / \mathrm{M} / 57 / \mathrm{OS}$ & 12 & 6 & & SF6 & $20 / 200$ & $20 / 70$ & $20 / 100$ & $\mathrm{C}$ & & 10 \\
\hline 14/M/67/OD & 10 & 6.5 & & C3F8 & $20 / 800$ & $20 / 800$ & $20 / 800$ & $\mathrm{~N}$ & & 8 \\
\hline 15/M/58/OS & 30 & 4.5 & & SF6 & $20 / 200$ & $20 / 200$ & $20 / 200$ & $\mathrm{~N}$ & & 10 \\
\hline $16 / \mathrm{M} / 88 / \mathrm{OS}$ & 30 & 7 & & SF6 & HM & $\mathrm{HM}$ & HM & $\mathrm{N}$ & & 10 \\
\hline $17 / \mathrm{F} / 65 / \mathrm{OS}$ & 13 & 6 & & C3F8 & CF & CF & $\mathrm{CF}$ & $\mathrm{N}$ & & 8 \\
\hline $18 / \mathrm{M} / 56 / \mathrm{OD}$ & 12 & 5.5 & & $\mathrm{C} 3 \mathrm{~F} 8$ & $\mathrm{CF}$ & CF & $\mathrm{CF}$ & $\mathrm{N}$ & & 10 \\
\hline 19/F/72/OD & 10 & 3 & $50 / 0.1$ & SF6 & $\mathrm{HM}$ & $20 / 70$ & $20 / 100$ & $\mathrm{C}$ & & 9 \\
\hline 20/F/77/OD & 30 & 5 & & SF6 & $20 / 100$ & $20 / 100$ & $20 / 200$ & $\mathrm{P}$ & & 8 \\
\hline $21 / \mathrm{M} / 87 / \mathrm{OD}$ & 20 & 6.5 & $50 / 0.1$ & $\mathrm{C} 3 \mathrm{~F} 8$ & CF & LS & LS & $\mathrm{N}$ & $\mathrm{E}$ & 19 \\
\hline 22/F/79/OD & 7 & 6 & & SF6 & $20 / 400$ & $20 / 100$ & $20 / 100$ & $\mathrm{C}$ & & 9 \\
\hline $23 / \mathrm{M} / 66 / \mathrm{OS}$ & 3 & 4 & $50 / 0.1$ & SF6 & CF & $20 / 100$ & $20 / 200$ & $\mathrm{C}$ & & 10 \\
\hline 24/M/88/OS & 13 & 7 & & SF6 & $20 / 200$ & $20 / 200$ & $20 / 800$ & $\mathrm{P}$ & VH & 10 \\
\hline $25 / \mathrm{M} / 67 / \mathrm{OD}$ & 90 & 5 & $50 / 0.05$ & SF6 & $20 / 800$ & $20 / 400$ & $20 / 200$ & $\mathrm{P}$ & & 15 \\
\hline $26 / \mathrm{M} / 67 / \mathrm{OS}$ & 10 & 6 & & SF6 & HM & $20 / 800$ & $20 / 800$ & $\mathrm{C}$ & $\mathrm{VH}$ & 12 \\
\hline $27 / \mathrm{F} / 52 / \mathrm{OS}$ & 30 & 4.5 & $25 / 0.1$ & SF6 & CF & $20 / 70$ & $20 / 400$ & $\mathrm{C}$ & & 8 \\
\hline $28 / \mathrm{M} / 53 / \mathrm{OS}$ & 5 & 4 & & SF6 & $20 / 100$ & $20 / 100$ & $20 / 200$ & $\mathrm{~N}$ & & 12 \\
\hline 29/F/72/OD & 21 & 4 & & SF6 & HM & $20 / 100$ & $20 / 200$ & $\mathrm{C}$ & & 10 \\
\hline $30 / \mathrm{M} / 54 / \mathrm{OD}$ & 4 & 6 & & SF6 & $20 / 400$ & $20 / 40$ & $20 / 100$ & $\mathrm{C}$ & & 11 \\
\hline $31 / \mathrm{M} / 51 / \mathrm{OD}$ & 60 & 8 & $25 / 0.1$ & SF6 & $20 / 100$ & $20 / 100$ & $20 / 400$ & $\mathrm{~N}$ & & 22 \\
\hline $32 / \mathrm{M} / 62 / \mathrm{OS}$ & 90 & 6 & & SF6 & $20 / 200$ & $20 / 400$ & $20 / 400$ & $\mathrm{~N}$ & & 7 \\
\hline $33 / \mathrm{F} / 72 / \mathrm{OS}$ & 12 & 5 & $50 / 0.1$ & SF6 & CF & $20 / 40$ & $20 / 100$ & $\mathrm{C}$ & & 10 \\
\hline $34 / F / 68 / O S$ & 30 & 7 & $25 / 0.05$ & SF6 & $\mathrm{CF}$ & $20 / 50$ & $20 / 100$ & C & & 14 \\
\hline 35/F/61/OD & 30 & 5 & $25 / 0.05$ & SF6 & $\mathrm{CF}$ & CF & CF & $\mathrm{C}$ & & 9 \\
\hline $36 / \mathrm{M} / 65 / \mathrm{OD}$ & 10 & 3 & & SF6 & CF & $20 / 400$ & $20 / 400$ & $\mathrm{P}$ & & 10 \\
\hline $37 / \mathrm{M} / 58 / \mathrm{OS}$ & 13 & 6 & $50 / 0.1$ & SF6 & HM & CF & CF & $\mathrm{P}$ & & 9 \\
\hline $38 / \mathrm{M} / 84 / \mathrm{OD}$ & 60 & 7.5 & $50 / 0.1$ & SF6 & $20 / 400$ & $20 / 400$ & $20 / 800$ & $\mathrm{~N}$ & & 10 \\
\hline $39 / \mathrm{M} / 75 / \mathrm{OD}$ & 60 & 4 & & SF6 & $20 / 100$ & $20 / 100$ & $20 / 800$ & $\mathrm{P}$ & & 20 \\
\hline 40/F/74/OS & 4 & 7 & $50 / 0.1$ & SF6 & $20 / 100$ & $20 / 40$ & $20 / 70$ & $\mathrm{C}$ & & 18 \\
\hline $41 / \mathrm{M} / 81 / \mathrm{OD}$ & 90 & 7 & $25 / 0.1$ & SF6 & CF & CF & CF & $\mathrm{N}$ & & 9 \\
\hline $42 / \mathrm{F} / 62 / \mathrm{OS}$ & 21 & 9 & & SF6 & $20 / 200$ & $20 / 400$ & $20 / 400$ & $\mathrm{~N}$ & & 9 \\
\hline 43/F/83/OS & 30 & 10 & & SF6 & CF & CF & CF & $\mathrm{N}$ & & 11 \\
\hline 44/M/61/OS & 12 & 7 & $25 / 0.1$ & SF6 & $20 / 800$ & $20 / 800$ & $20 / 800$ & $\mathrm{P}$ & & 10 \\
\hline $45 / \mathrm{M} / 55 / \mathrm{OS}$ & 30 & 5 & & SF6 & $20 / 100$ & $20 / 100$ & $20 / 200$ & $\mathrm{~N}$ & & 9 \\
\hline $46 / \mathrm{M} / 85 / \mathrm{OD}$ & 10 & 6.5 & & SF6 & $20 / 200$ & $20 / 200$ & $20 / 800$ & $\mathrm{~N}$ & & 20 \\
\hline $47 / \mathrm{M} / 82 / \mathrm{OD}$ & 30 & 7 & $25 / 0.1$ & SF6 & $20 / 200$ & $20 / 200$ & $20 / 400$ & $\mathrm{~N}$ & & 10 \\
\hline $48 / \mathrm{M} / 53 / \mathrm{OS}$ & 10 & 5 & $25 / 0.1$ & SF6 & $20 / 400$ & $20 / 40$ & $20 / 100$ & $\mathrm{C}$ & & 8 \\
\hline $49 / \mathrm{M} / 56 / \mathrm{OD}$ & 12 & 6 & $25 / 0.1$ & SF6 & $20 / 800$ & $20 / 40$ & $20 / 100$ & $\mathrm{C}$ & & 10 \\
\hline 50/F/63/OD & 30 & 5 & $25 / 0.1$ & SF6 & CF & CF & CF & $\mathrm{N}$ & & 6 \\
\hline $51 / \mathrm{F} / 62 / \mathrm{OS}$ & 7 & 8 & & SF6 & CF & $20 / 50$ & $20 / 200$ & $\mathrm{C}$ & & 12 \\
\hline $52 / \mathrm{F} / 67 / \mathrm{OD}$ & 30 & 3 & & SF6 & $20 / 800$ & $20 / 800$ & $20 / 800$ & $\mathrm{~N}$ & & 10 \\
\hline 53/F/57/OS & 30 & 7 & & SF6 & $\mathrm{CF}$ & CF & $\mathrm{CF}$ & $\mathrm{N}$ & & 6 \\
\hline
\end{tabular}

C, complete displacement; $\mathrm{CF}$, counting finger; $\mathrm{DD}$, disc diameters; HM, hand motion; LS, light sense; N, no displacement; OD, right eye; OS, left eye; $\mathrm{P}$, partial displacement; $\mathrm{VH}$, vitreous haemorrhage. 
Table 2 Baseline patient characteristics

\begin{tabular}{|c|c|c|c|c|c|c|c|}
\hline \multirow{2}{*}{$\begin{array}{l}\text { Variables } \\
\text { Haemorrhage duration }\end{array}$} & \multicolumn{2}{|c|}{$t-P A+g a s(\mathrm{n}=28)$} & \multicolumn{2}{|c|}{ Gas alone $(\mathrm{n}=25)$} & \multirow[t]{2}{*}{$\#$} & \multirow[t]{2}{*}{$\S$} & \multirow[t]{2}{*}{ ฯ } \\
\hline & $\begin{array}{l}<14 \text { days } \\
(n=15)\end{array}$ & $\begin{array}{l}>14 \text { days } \\
(n=13)\end{array}$ & $\begin{array}{l}<14 \text { days } \\
(n=13)\end{array}$ & $\begin{array}{l}>14 \text { days } \\
(n=12)\end{array}$ & & & \\
\hline Gender male, $n(\%)$ & $8(53.3)$ & $7(53.8)$ & $10(76.9)$ & $6(50.0)$ & 0.44 & 0.25 & 0.85 \\
\hline Total $n(\%)$ & \multicolumn{2}{|c|}{$15(53.6)$} & \multicolumn{2}{|c|}{$16(64.0)$} & & & \\
\hline Age (years), mean (SD) & $60.67(1.97)$ & $69.69(3.40)$ & $67.15(3.19)$ & $68.17(3.10)$ & 0.36 & 0.09 & 0.75 \\
\hline Total (years), mean (SD) & \multicolumn{2}{|c|}{$64.86(2.05)$} & \multicolumn{2}{|c|}{$67.64(2.19)$} & & & \\
\hline $\begin{array}{l}\text { Duration of symptoms } \\
\text { (days), mean (SD) }\end{array}$ & $8.73(0.92)$ & $47.69(7.44)$ & $9.38(0.80)$ & $35.25(5.78)$ & 0.43 & 0.59 & 0.2 \\
\hline Total (days), mean (SD) & \multicolumn{2}{|c|}{$26.82(5.06)$} & \multicolumn{2}{|c|}{$21.80(3.81)$} & & & \\
\hline \multicolumn{8}{|l|}{ Preoperative visual acuity, $n$} \\
\hline$<2 / 200$ & 6 & 4 & 2 & 3 & 0.44 & 0.26 & 0.58 \\
\hline $2 / 200-20 / 200$ & 6 & 7 & 9 & 5 & & & \\
\hline$>20 / 200$ & 3 & 2 & 2 & 4 & & & \\
\hline Area of SRH (DD), mean (SD) & $5.83(0.42)$ & $5.73(0.41)$ & $5.73(0.37)$ & $5.88(0.60)$ & 0.98 & 0.86 & 0.84 \\
\hline Total (DD), mean (SD) & \multicolumn{2}{|c|}{$5.79(0.29)$} & \multicolumn{2}{|c|}{$5.80(0.34)$} & & & \\
\hline $\begin{array}{l}\text { Follow-up, mean number of } \\
\text { months (SD) }\end{array}$ & $12.33(1.24)$ & $13.38(1.51)$ & $11.38(0.92)$ & $10.17(1.01)$ & 0.10 & 0.56 & 0.10 \\
\hline Total number of months (SD) & \multicolumn{2}{|c|}{$12.82(0.96)$} & \multicolumn{2}{|c|}{$10.80(0.68)$} & & & \\
\hline
\end{tabular}

$\mathrm{DD}$, disc diameter; $\mathrm{SRH}$, subretinal haemorrhage.

\#, between 't-PA + gas' group and 'gas-alone' group.

$\S$, between 't-PA + gas' group and 'gas-alone' group in haemorrhage duration $<14$ days.

๑, between 't-PA + gas' group and 'gas-alone' group in haemorrhage duration $>14$ days.

Continuous variables were compared across groups by two-sample Student's $t$-test. Discrete variables were analysed by $\chi^{2}$ test or Fisher's exact test.

analysed using the $\chi^{2}$ test or the Fisher's exact test. Values of $P<0.05$ were considered significant. Multiple logistic regression analysis was performed to determine baseline factors predictive of best postoperative visual acuity improved by two or more Snellen lines.

\section{Results}

A total of 53 eyes of 53 patients were included in this study (Table 1). Twenty-eight eyes underwent intravitreal t-PA and gas injection (t-PA and gas group); 25 eyes underwent intravitreal gas injection alone (gas-alone group).

Baseline characteristics for the two groups are presented in Table 2. There are no statistically significant differences between the two groups with regard to gender, age, or duration and area of haemorrhage $(P=0.44,0.36,0.43$, and 0.98 , respectively).

Fifteen eyes (53.6\%) in the t-PA and gas group and 13 eyes $(52.0 \%)$ in the gas-alone group experienced a haemorrhage for fewer than 14 days. Here, we found no statistically significant differences between the two groups with regard to gender, age, duration of haemorrhage, and extent of haemorrhage $(P=0.25,0.09$, 0.59 , and 0.86 , respectively). We also found no statistically significant differences between the two groups in those eyes with haemorrhage duration of more than 14 days ( $P=0.85,0.75,0.20$, and 0.84 for gender, age, duration of haemorrhage, and extent of haemorrhage, respectively).

\section{Visual outcomes}

Best postoperative visual acuity and final visual acuity were plotted against preoperative visual acuity (Figure 1). After treatment, the average time to achieve best postoperative visual acuity was 1.2 months.

In the t-PA and gas group, 17 of 28 eyes (60.7\%) showed improvement in best postoperative visual acuity (that is, exhibited an increase of two or more Snellen lines), 10 eyes (35.7\%) remained the same, while 1 eye (3.6\%) worsened (that is, exhibited a decrease of two or more Snellen lines). In the gas-alone group, 8 of 25 eyes (32.0\%) showed improvement and 17 eyes (68.0\%) were stable. Eyes treated with t-PA and gas were more likely than those treated with gas alone to show improvement in best postoperative visual acuity $(X=4.37, P=0.037$; Fisher's exact test).

In those eyes with haemorrhage duration of fewer than 14 days, the incidence of improvement was not statistically different between the two groups (73.3 vs $53.8 \% ; P=0.28$; Fisher's exact test). In those with haemorrhage duration of more than 14 days, the incidence of improvement in the t-PA and gas group was significantly higher than in the gas-alone group (46.2 vs 8.3\%; $P=0.035$; Fisher's exact test).

At the final postoperative visit, the visual acuity had improved in 12 of 28 eyes in the t-PA and gas group $(42.9 \%)$, remained the same in 14 eyes $(50.0 \%)$, and worsened in 2 eyes (7.1\%). In the gas-alone group, 7 of 25 eyes $(28.0 \%)$ improved, 16 eyes $(64.0 \%)$ remained the 
a

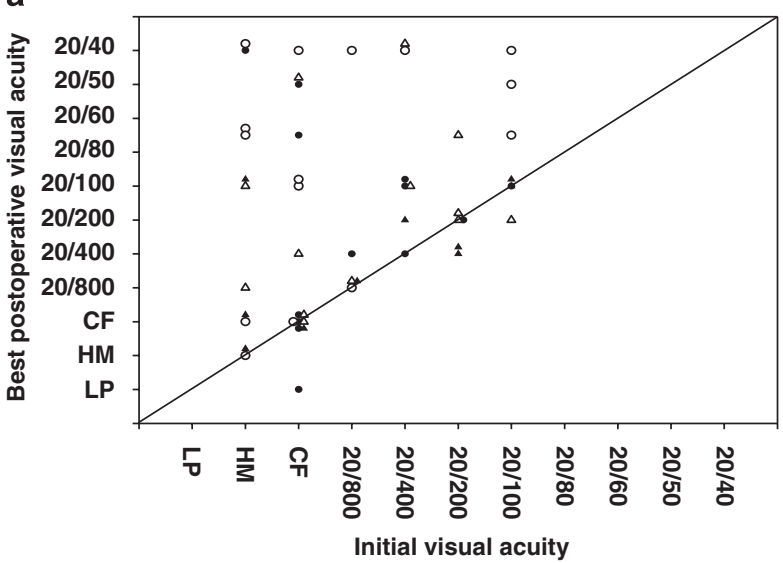

b

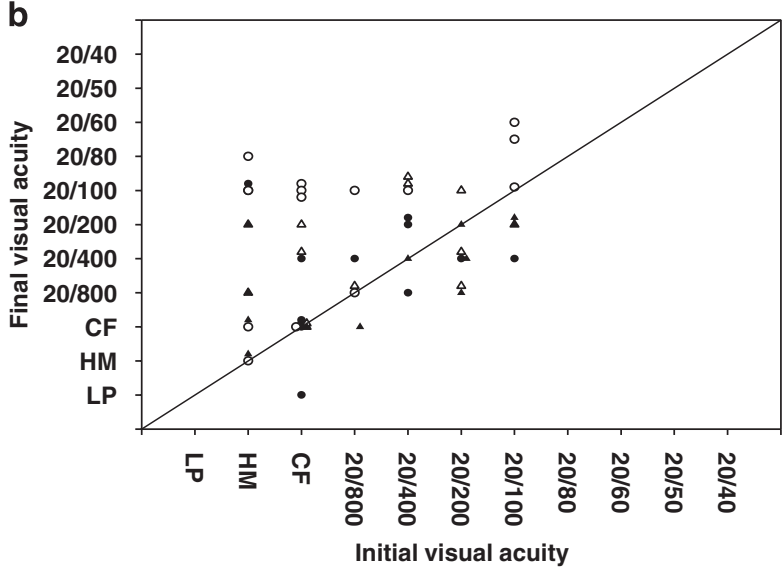

Figure 1 (a) Best postoperative visual acuity plotted against preoperative visual acuity. (b) Final postoperative visual acuity (visual acuity at last follow-up) plotted against preoperative visual acuity. $\bigcirc$ indicates eyes with haemorrhage lasting less than 14 days treated with pneumatic displacement with intravitreous tissue plasminogen activator (t-PA) injection. indicates eyes with haemorrhage lasting more than 14 days treated with pneumatic displacement with intravitreous t-PA injection. $\triangle$ indicates eyes with haemorrhage lasting less than 14 days treated with pneumatic displacement without t-PA. indicates eyes with haemorrhage lasting more than 14 days treated with pneumatic displacement without t-PA. LP, light perception; $\mathrm{HM}$, hand motion; $\mathrm{CF}$, counting fingers.

same, and 2 eyes $(8.0 \%)$ worsened. The incidence of improvement was not statistically different between the two groups ( $X=1.27, P=0.39$; Fisher's exact test).

Analysis of eyes with haemorrhage duration of fewer than 14 days revealed that final visual acuity improved by two or more Snellen lines in $60.0 \%$ of 15 eyes in the t-PA and gas group and $46.2 \%$ of 13 eyes in the gas-alone group ( $X=0.54, P=0.46 ; \chi^{2}$ test). In those eyes with haemorrhage duration of more than 14 days, there was still no significant difference between the two groups (23.1 vs 8.3\%; $P=0.32$; Fisher's exact test) (Figure 2).

The distribution of the mean visual acuity at preoperative, 1, 6 months and final visit for the different subgroups of eyes is shown in Table 3. Among the four subgroups, eyes with haemorrhage duration of more than 14 days and treated with gas alone obtained the least improvement in mean visual acuity from preoperative to 1 month postoperatively. Furthermore, there was a tendency that the mean visual acuity decreased gradually from 1 month to final visit in four treatment groups.

\section{Anatomic outcomes}

In the t-PA and gas group, complete displacement was achieved in 14 of 28 eyes $(50.0 \%)$, partial displacement in 9 eyes $(32.1 \%)$, and no displacement in 5 eyes (17.9\%). In the gas-alone group, complete displacement was achieved in 6 of 25 eyes (24.0\%), partial displacement in 7 eyes $(28.0 \%)$, and no displacement in 12 eyes $(48.0 \%)$. There was a borderline significant difference between the two groups with respect to the incidence of complete displacement $\left(X=3.8, P=0.05 ; \chi^{2}\right.$ test). However, the incidence of no displacement in the t-PA and gas group was significantly lower than in the gas-alone group ( $X=5.51, P=0.019 ; \chi^{2}$ test).

In those eyes with haemorrhage duration of fewer than 14 days, the incidence of complete displacement was not significantly different between the two groups (60.0 vs $38.4 \% ; P=0.26)$. Nor was the incidence of no displacement significantly different (20.0 vs $23.2 \%$; $P=0.84$; Fisher's exact test)

In those eyes with haemorrhage duration of more than 14 days, the t-PA and gas group exhibited a higher incidence of complete displacement than the gas-alone group, although the difference between the two groups did not reach significance (38.4 vs $8.3 \%$; $P=0.078$; Fisher's exact test). However, the incidence of no displacement was significantly lower in the t-PA and gas group than in the gas-alone group (15.4 vs $75.1 \%$; $P=0.048$; Fisher's exact test) (Figure 3).

On final follow-up, atrophic macular changes were found in 13 of 28 eyes (46.4\%), fibrous disciform scarring in 13 eyes $(46.4 \%)$, and subfoveal fibrovascular pigment epithelial detachment in 2 eyes $(7.2 \%)$ in the t-PA and gas group. In the gas-alone group, 11 of 25 eyes (44.0\%) developed atrophic macular changes, 13 eyes $(52.0 \%)$ had fibrous disciform scarring, and 1 eye (4.0\%) developed subfoveal fibrovascular pigment epithelial detachment. There was no statistically significant difference in final macular status between the two groups $(X=0.3, P=0.85$; Fisher's exact test).

\section{Complications}

Breakthrough vitreous haemorrhage was found in 1 of 28 eyes $(3.6 \%)$. in the t-PA and gas group, and in 2 of 25 eyes 

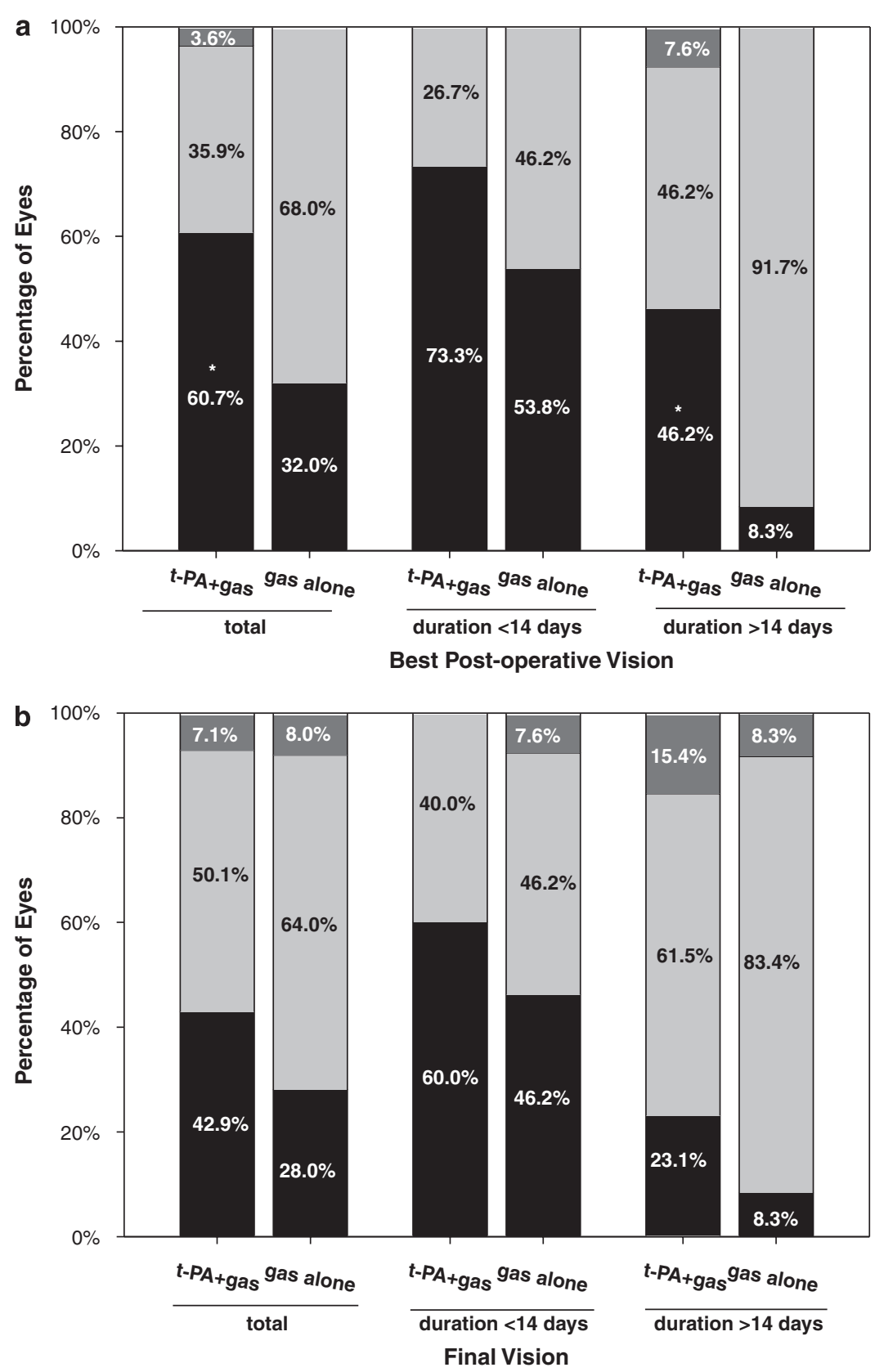

Figure 2 Comparison of postoperative best (a) and final (b) visual outcomes between treatment with pneumatic displacement with ( $t$ PA and gas group) and without (gas-alone group) intravitreous t-PA injection in all eyes included, subgroup of eyes with haemorrhage lasting fewer than 14 days and subgroup of eyes with haemorrhage lasting more than 14 days. Black bar segments denote improvement by two or more Snellen lines. Light-grey segments show that eyes remained the same or within two lines from baseline visual acuity. Dark-grey segments show loss of two or more Snellen lines. ${ }^{*} P$-value $<0.05, \chi^{2}$ test or Fisher's exact test.

$(8.0 \%)$ in the gas-alone group. There was no statistically significant difference between the two groups with respect to the occurrence of vitreous haemorrhage ( $X=0.49, P=0.60$; Fisher's exact test). All of the cases of vitreous haemorrhage were mild and the patients recovered spontaneously within a few weeks, with no need for additional surgery.
One eye in the t-PA and gas group developed staphylococcal endophthalmitis 3 days after the initial injection. Additional surgery with pars plana vitrectomy and intravitreal injection of vancomycin was performed. Though the infection was resolved, the patient's visual acuity remained poor with light perception only. 
Table 3 Distribution of mean visual results

\begin{tabular}{llcllr}
\hline & \multicolumn{2}{c}{$t-P A+$ gas $(\mathrm{n}=28)$} & & Gas alone $(\mathrm{n}=25)$ \\
\cline { 2 - 3 } & \multicolumn{1}{c}{$<14$ days $(\mathrm{n}=15)$} & $>14$ days $(\mathrm{n}=13)$ & & $<14$ days $(\mathrm{n}=13)$ & $>14$ days $(\mathrm{n}=12)$ \\
\hline Preoperative & $1.99 \pm 0.22^{*}(20 / 146)$ & $1.72 \pm 0.16(20 / 110)$ & & $1.84 \pm 0.25(20 / 126)$ & $1.50 \pm 0.24(20 / 90)$ \\
1 month & $0.96 \pm 0.24(20 / 52)$ & $1.28 \pm 0.28(20 / 72)$ & & $1.06 \pm 0.16(20 / 58)$ & $1.33 \pm 0.21(20 / 76)$ \\
6 months & $1.07 \pm 0.15(20 / 57)$ & $1.40 \pm 0.25(20 / 83)$ & & $1.21 \pm 0.15(20 / 67)$ & $1.45 \pm 0.23(20 / 86)$ \\
Final visit & $1.17 \pm 0.19(20 / 62)$ & $1.50 \pm 0.24(20 / 92)$ & & $1.29 \pm 0.13(20 / 73)$ & $1.50 \pm 0.17(20 / 90)$ \\
\hline
\end{tabular}

${ }^{*}$ Numbers on the left side of each column are mean logarithm of minimum angle of resolution (log MAR)-converted visual acuities \pm SD. Snellen equivalent of the mean log MAR-converted visual acuity in parentheses to the right of each log MAR number.

Elevated intraocular pressure was observed in 2 of 28 eyes $(7.1 \%)$ in the t-PA and gas group and 1 of 25 eyes $(4.0 \%)$ in the gas-alone group. There was no statistically significant difference between the two groups $(X=0.24$, $P=0.54$; Fisher's exact test). The intraocular pressure in these patients was $23-25 \mathrm{~mm} \mathrm{Hg}$ during the first three postoperative days. However, none of the patients, in either group, required treatment with anti-glaucomatous medications.

Other than that, no recurrent haemorrhage or procedure-related complications were observed in either group. Furthermore, there was no clinical evidence of retinal or retinal pigment epithelial toxicity with the use of intravitreal t-PA injection.

\section{Factors predicting best postoperative visual acuity with} improvement of two or more Snellen lines

A multiple logistic regression of the preoperative variables was performed to analyse the primary outcome variable, improvement in best visual acuity by two or more lines. This analysis showed that shorter haemorrhage duration was significantly correlated with a higher percentage of eyes exhibiting improvement in best visual acuity by two or more lines $(\mathrm{OR}=9.02, P=0.015)$. Whether or not t-PA was used was of borderline significance $(\mathrm{OR}=4.69, P=0.046)$. No statistically significant difference was found with regard to age of onset $(\mathrm{OR}=2.06, P=0.56)$, area of submacular haemorrhage $(\mathrm{OR}=2.03, P=0.41)$, type of gas $(\mathrm{OR}=5.96, P=0.23)$, or initial visual acuity $(\mathrm{OR}=0.70$, $P=0.73$ ) (Table 4).

\section{Discussion}

In this study, we demonstrated that intravitreal t-PA and gas injection led to better anatomic and postoperative visual outcomes than gas injection alone. However, subgroup analysis revealed that the benefits were significant only in eyes with haemorrhage duration of more than 14 days - not in those with haemorrhage duration of fewer than 14 days. These results indicate that intravitreal t-PA is valuable for assisting gas displacement of submacular haemorrhage only in eyes with relatively old haemorrhage. Notably, the final visual outcomes of the two groups were similar, regardless of which subgroups were compared. Taken together, these results suggest that intravitreal t-PA offers patients with relatively old haemorrhage a better chance of promptly recovering their vision, but fails to change the final visual outcomes.

The aim of using intravitreal injection of t-PA as an adjunct to gas displacement of submacular haemorrhage is to produce enzyme-induced lysis of the blood clots first by t-PA, facilitating subsequent mechanical displacement of liquefied blood by the gas bubble. ${ }^{24}$ It is likely that, in an eye with a relatively fresh haemorrhage, the clot has been soft enough to allow sufficient movement by gas alone. Therefore, the effects of t-PAinduced subretinal fibrinolysis may be less apparent, or perhaps unnecessary for eyes with fresh submacular haemorrhage. This could explain our observations that intravitreal t-PA provided additional benefits for vision recovery only in eyes with haemorrhage duration of more than 14 days.

Several pilot studies have suggested that intravitreous injection of gas alone may be effective in displacing submacular blood. However, most of the successfully treated cases described in these studies involved haemorrhages of fewer than 14 days. Daneshvar et $a l^{25}$ reported three cases in which significant displacement of subretinal haemorrhage was achieved using intravitreous gas alone; two of the three involved haemorrhages of fewer than 14 days. Ohji et $a l^{23}$ reported the beneficial effects of gas without t-PA on in-patients with submacular haemorrhage, but none of the successfully treated patients had a haemorrhage of more than 14 days. The results implied that it might not be possible to displace solid blood clots from older haemorrhages with gas compression alone. In this study as well, we demonstrated that only a few eyes (8.3\%) with a haemorrhage of more than 14 days benefited from the use of intravitreous gas without $t-P A$. This finding emphasizes the necessity of using intravitreous t-PA to assist the displacement of submacular blood in eyes with long-lasting haemorrhage. 

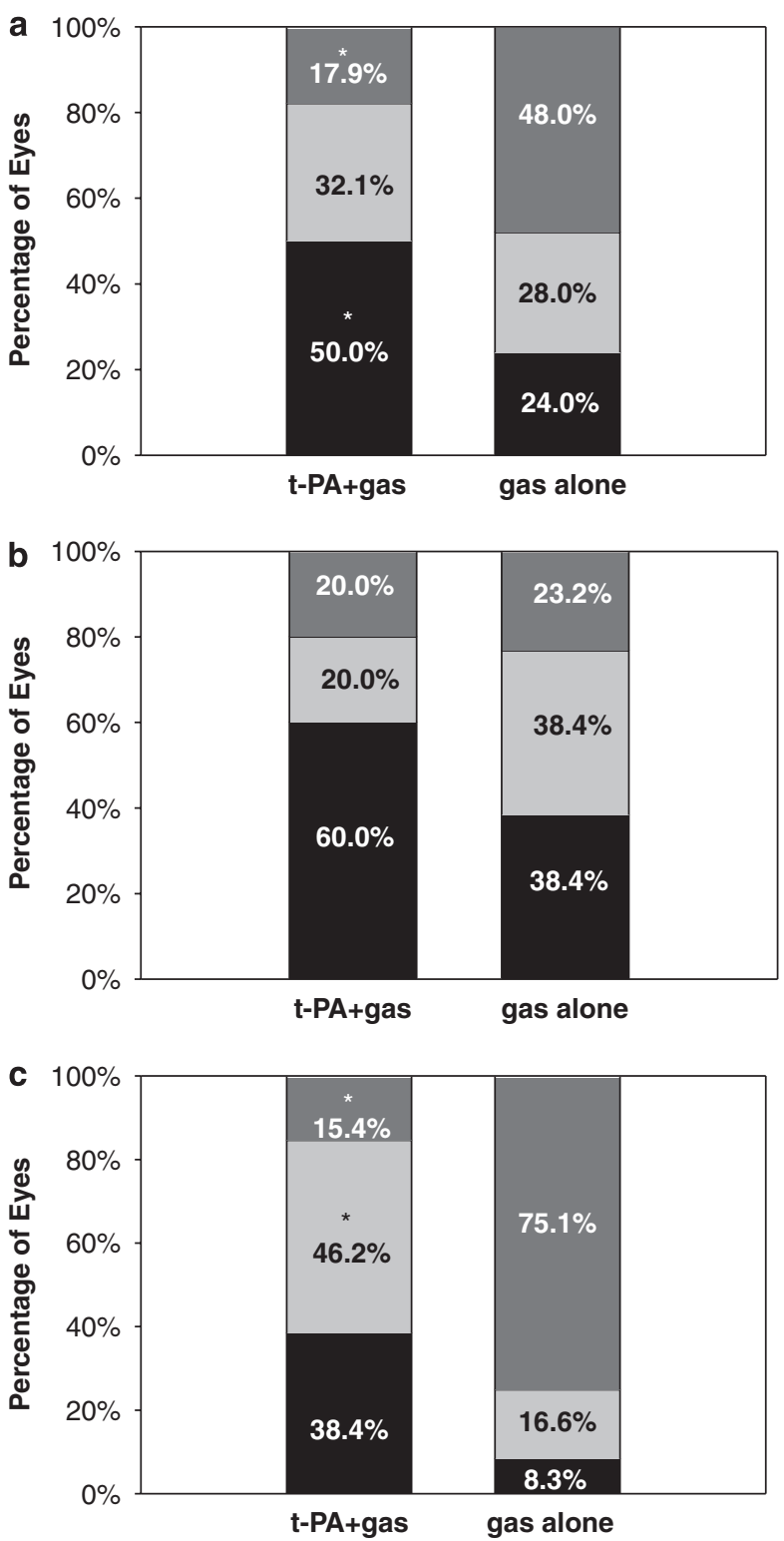

Figure 3 Comparison of anatomic outcomes between treatment with pneumatic displacement with (t-PA and gas group) and without (gas-alone group) intravitreous t-PA injection in all eyes included (a), subgroup of eyes with haemorrhage lasting fewer than 14 days (b), and subgroup of eyes with haemorrhage lasting more than 14 days (c). Complete displacement (black bar segments) was defined as blood clearance of more than $90 \%$ from the subfoveal space, partial displacement (light grey segments) as $20-90 \%$ clearance, and no displacement (dark grey segments) as less than $20 \%$ displacement. ${ }^{*} P$-value $<0.05, \chi^{2}$ test or Fisher's exact test.

Our results demonstrated that use of t-PA did not improve the final result of gas displacement of submacular haemorrhage. Although such use yielded dramatic displacement of the submacular blood, accompanied by promising visual recovery in some eyes,
Table 4 Multivariate analysis for risk factors for eyes improved two or more Snellen lines in postoperative best visual acuity

\begin{tabular}{|c|c|c|}
\hline Variables & $\begin{array}{l}\text { Odds ratio }(95 \% \\
\text { confidence interval) }\end{array}$ & P-value \\
\hline \multicolumn{3}{|l|}{ Age (years) } \\
\hline$<65$ vs $>65$ & $2.06(0.49-17.67)$ & 0.56 \\
\hline \multicolumn{3}{|l|}{ Treatment } \\
\hline $\mathrm{t}-\mathrm{PA}+$ gas $v s$ gas alone & $4.69(0.88-25.00)$ & $0.046^{*}$ \\
\hline \multicolumn{3}{|l|}{ Haemorrhage duration } \\
\hline$<14$ days $v s>14$ days & $9.02(1.53-53.10)$ & $0.015^{*}$ \\
\hline \multicolumn{3}{|l|}{ Area of haemorrhage } \\
\hline$<4 \mathrm{DD} v s>4 \mathrm{DD}$ & $2.03(0.38-10.97)$ & 0.41 \\
\hline \multicolumn{3}{|l|}{ Type of gas } \\
\hline SF6 vs C3F8 & $5.96(0.33-107.93)$ & 0.23 \\
\hline \multicolumn{3}{|l|}{ Pre-op VA } \\
\hline$>20 / 200$ vs $<2 / 200$ & $0.70(0.08-6.55)$ & 0.73 \\
\hline $2 / 200-20 / 200$ vs $<2 / 200$ & $0.65(0.06-7.02)$ & 0.76 \\
\hline
\end{tabular}

$\mathrm{DD}$, disc diameter; VA, visual acuity.

${ }^{*} P$-value $<0.05$.

further follow-up revealed a trend towards gradual decline in visual acuity, indicating that final visual outcome depends in large part on the natural course of the underlying disease. It is noteworthy to mention, however, that the final visual outcome data should be interpreted with caution. In this study, the follow-up periods varied considerably, and this may have greatly influenced the final visual outcomes. In addition, with the prosperous development of anti-vascular endothelial growth factor therapy, more eyes may be expected to be stabilized at their best post-treatment levels by more effective treatments of the underlying neovascular process.

The potential for retinal toxicity remains a serious concern in intravitreous injection of commercially available t-PA. Several investigators have shown that intravitreous injections of high concentrations of t-PA may be unsafe. ${ }^{16-19,26-28}$ In this study, to reduce the probability of damaging effects with intravitreous t-PA, we chose $25-50 \mu \mathrm{g} / \mathrm{ml}$ as the range of optimal doses. No retinal pigmentary changes and unexplained visual acuity loss were found, suggesting that concentrations of less than $50 \mu \mathrm{g} / 0.1 \mathrm{ml}$ were safe for displacement of submacular haemorrhage in AMD patients.

Multivariate logistic regression analysis demonstrated that early treatment (within 14 days) was significantly associated with better postoperative visual outcomes. However, whether or not t-PA was used was of borderline significance. These findings indicated that 
early treatment is a more important predictor of better postoperative vision than t-PA usage. In addition, adjunctive intravitreal $t$-PA injection may increase the risk of complications such as endophthalmitis, retinal break, and retinal detachment. ${ }^{29,30}$ Because the efficacy and safety of adjunctive t-PA within 14 days are still open questions, we suggest a staged procedure in which only intravitreal gas is injected initially. The use of t-PA is reserved only for those cases in which intravitreal gas alone fails to produce adequate displacement of submacular clot after $48 \mathrm{~h}$ of lying in a face-down position. ${ }^{31}$ This result is consistent with findings by Hassan $e t \mathrm{al}^{32}$ and Johnson, ${ }^{33}$ who also proposed treatment strategies using t-PA only after unsuccessful displacement of submacular haemorrhage with gas alone (24-48 h afterward).

The current study was limited by a relatively small number of patients and a retrospective study design. For the small size of our subject population, the power of the statistical tests was low, leading to the result that only large differences in the number of postoperative vision improvements and complications might be recognized as significant. Furthermore, the retrospective design may have resulted in an unforeseen selection bias, because of the nonrandomized assignment of patients to treatment groups. However, the effects of any selection bias were likely minimal as the preoperative patient demographics and eye characteristics in the two groups were similar. Nonetheless, further large prospective randomized clinical trials are needed to clarify the precise role of adjunctive intravitreous t-PA.

In summary, our results suggest that use of intravitreal t-PA led to better postoperative visual improvement than can be achieved without t-PA. These benefits were mainly confined to those eyes with relatively old haemorrhage, however (more than 14 days in this study). There was no statistically significant benefit with respect to final visual acuity. Treatment with thick submacular haemorrhage at an early stage ( $<14$ days) contributed to better postoperative vision. A staged procedure is suggested, especially for those with haemorrhage duration of fewer than approximately 14 days; $\mathrm{t}-\mathrm{PA}$ is used only after unsuccessful displacement of submacular haemorrhage with initially injected gas $(24-48 \mathrm{~h}$ afterward).

\section{References}

1 Berrocal MH, Lewis ML, Flynn Jr HW. Variations in the clinical course of submacular hemorrhage. Am J Ophthalmol 1996; 122: 486-493.

2 Avery RL, Fekrat S, Hawkins BS, Bressler NM. Natural history of subfoveal subretinal hemorrhage in age-related macular degeneration. Retina 1996; 16: 183-189.
3 Bennett SR, Folk J, Blodi CF, Klugman M. Factors prognostic of visual outcome in patients with subretinal hemorrhage. Am J Ophthalmol 1990; 109: 33-37.

4 Scupola A, Coscas G, Soubrane G, Balestrazzi E. Natural history of macular subretinal hemorrhage in age-related macular degeneration. Ophthalmologica 1999; 213: 97-102.

5 Glatt H, Machemer R. Experimental subretinal hemorrhage in rabbits. Am J Ophthalmol 1982; 94: 762-773.

6 Toth CA, Morse LS, Hjelmeland LM, Landers III MB. Fibrin directs early retinal damage after experimental subretinal hemorrhage. Arch Ophthalmol 1991; 109: 723-729.

7 Lewis H. Intraoperative fibrinolysis of submacular hemorrhage with tissue plasminogen activator and surgical drainage. Am J Ophthalmol 1994; 118: 559-568.

8 Kamei M, Tano Y, Maeno T, Ikuno Y, Mitsuda H, Yuasa T. Surgical removal of submacular hemorrhage using tissue plasminogen activator and perfluorocarbon liquid. Am J Ophthalmol 1996; 121: 267-275.

9 Chaudhry NA, Mieler WF, Han DP, Alfaro 3rd VD, Liggett PE. Preoperative use of tissue plasminogen activator for large submacular hemorrhage. Ophthalmic Surg Lasers 1999; 30: $176-180$.

10 Johnson MW, Olsen KR, Hernandez E. Tissue plasminogen activator treatment of experimental subretinal hemorrhage. Retina 1991; 11: 250-258.

11 Johnson MW, Olsen KR, Hernandez E. Tissue plasminogen activator thrombolysis during surgical evacuation of experimental subretinal hemorrhage. Ophthalmology 1992; 99: $515-521$.

12 Heriot WJ. Intravitreal gas and tPA: an outpatient procedure for submacular hemorrhage. Paper presented at American Academy of Ophthalmology Annual Vitreoretinal Update; October 1996; Chicago, IL.

13 Meier P, Zeumer C, Jochmann C, Wiedemann P. Management of submacular hemorrhage by tissue plasminogen activator and SF6 gas injection. Ophthalmologe 1999; 96: 643-647.

14 Krepler K, Kruger A, Tittl M, Stur M, Wedrich A. Intravitreal injection of tissue plasminogen activator and gas in subretinal hemorrhage caused by age-related macular degeneration. Retina 2000; 20: 251-256.

15 Hattenbach LO, Klais C, Koch FH, Gumbel HO. Intravitreous injection of tissue plasminogen activator and gas in the treatment of submacular hemorrhage under various conditions. Ophthalmology 2001; 108: 1485-1492.

16 Johnson MW, Olsen KR, Hernandez E, Irvine WD, Johnson RN. Retinal toxicity of recombinant tissue plasminogen activator in the rabbit. Arch Ophthalmol 1990; 108: $259-263$.

17 Irvine WD, Johnson MW, Hernandez E, Olsen KR. Retinal toxicity of human tissue plasminogen activator in vitrectomized rabbit eyes. Arch Ophthalmol 1991; 109: 718-722.

18 Hrach CJ, Johnson MW, Hassan AS, Lei B, Sieving PA, Elner VM. Retinal toxicity of commercial intravitreal tissue plasminogen activator solution in cat eyes. Arch Ophthalmol 2000; 118: 659-663.

19 Chen SN, Yang TC, Ho CL, Kuo YH, Yip Y, Chao AN. Retinal toxicity of intravitreal tissue plasminogen activator. Opthalmol 2003; 110: 704-708.

20 Takeuchi A, Kricorian G, Yao XY, Kenny JW, Marmor MF. The rate and source of albumin entry into saline-filled experimental retinal detachments. Invest Ophthalmol Vis Sci 1994; 35: 3792-3798. 
21 Boone DE, Boldt HC, Ross RD, Folk JC, Kimura AE. The use of intravitreal tissue plasminogen activator in the treatment of experimental subretinal hemorrhage in the pig model. Retina 1996; 16: 518-524.

22 Kamei M, Misono K, Lewis H. A study of the ability of tissue plasminogen activator to diffuse into the subretinal space after intravitreal injection in rabbits. Am J Ophthalmol 1999; 128: 739-746.

23 Ohji M, Saito Y, Hayashi A, Lewis JH, Tano Y. Pneumatic displacement of subretinal hemorrhage without tissue plasminogen activator. Arch Ophthalmol 1998; 116: 1326-1332.

24 Haupert CL, McCuen II BW, Jaffe GJ, Steller ER, Cox TA, Toth CA et al. Pars plana vitrectomy, subretinal injection of tissue plasminogen activator, and fluid-gas exchange for displacement of thick submacular hemorrhage in agerelated macular degeneration. Am J Ophthalmol 2001; 131: 208-215.

25 Daneshvar H, Kertes PJ, Leonard BC, Peyman GA. Management of submacular hemorrhage with intravitreal sulfur hexafluoride: a pilot study. Can J Ophthalmol 1999; 34: 385-388.

26 Tennat MTS, Borrillo JL, Regillo CD. Management of submacular hemorrahge. Ophthalmol Clin N Am 2002; 15 $445-452$.
27 Hesse L, Schmidt J, Kroll P. Management of acute submacular hemorrhage using recombinant tissue plasminogen activator and gas. Graefes Arch Clin Exp Ophthalmol 1999; 237: 273-277.

28 Handwerger BA, Blodi BA, Chandra AR, Olsen TW, Stevens TS. Treatment of submacular hemorrhage with low-dose intravitreal tissue plasminogen activator injection and pneumatic displacement. Arch Ophthalmol 2001; 119: 28-32.

29 Wirostko W, Han D, Perkins S. Complications of pneumatic retinopexy. Curr Opin Ophthalmol 2000; 11: 195-200.

30 Vote BJ, Buttery R, Polkinghorne PJ. Endophthalmitis after intravitreal injection of frozen preprepared tissue plasminogen activator (tPA) for pneumatic displacement of submacular hemorrhage. Retina 2004; 24: 808-809.

31 Borrillo JL, Regillo CD. Treatment of subretinal hemorrhage with tissue plasminogen activator. Curr Opin Ophthalmol 2001; 12: 207-211.

32 Hassan AS, Johnson MW, Schneiderman TE, Regillo CD, Tornambe PE, Poliner LS et al. Management of submacular hemorrhage with intravitreous tissue plasminogen activator injection and pneumatic displacement. Ophthalmology 1999; 106: 1900-1906.

33 Johnson MW. Pneumatic displacement of submacular hemorrhage. Curr Opin Ophthalmol 2000; 11: 201-206. 